Ciência Florestal, Santa Maria, v. 23, n. 4, p. 691-701, out.-dez., 2013

ISSN 0103-9954

\title{
CONCENTRAÇÃO DAS EXPORTAÇÕES MUNDIAIS DE PRODUTOS FLORESTAIS
}

\author{
CONCENTRATION OF WORLD EXPORTS OF FOREST PRODUCTS
}

\author{
Luiz Moreira Coelho Junior ${ }^{1}$ José Luiz Pereira de Rezende ${ }^{2}$ Antônio Donizette de Oliveira ${ }^{3}$
}

\begin{abstract}
RESUMO
Este trabalho analisou o grau de concentração das exportações mundiais de produtos florestais no período 1961 - 2008. Os dados utilizados estão disponíveis na Organização das Nações Unidas para Agricultura e Alimento. O grau de concentração foi determinado por meio da Razão de Concentração $[C R(k)]$, Índice de Herfindahl-Hirschman $(H H I)$, Índice de Entropia de Theil $(E)$ e Índice de Gini $(G)$. As principais conclusões foram: A participação brasileira nas exportações mundiais no agregado de produtos florestais é crescente ao longo do tempo; os setores mais significativos do agregado das exportações mundiais de produtos florestais, em ordem decrescente, foram o de celulose, madeira serrada, papel e papelão, painéis de madeira, madeira para fins industriais e energia. Segundo a classificação de Bain, a Razão de Concentração dos quatro e oito maiores exportadores de produtos florestais é moderadamente baixa; os indicadores $H H I$ e de Entropia de Theil $(E)$ mostram redução na concentração das exportações mundiais de produtos florestais e maior competição entre os países que comercializam tais produtos; o Índice de Gini indica que, apesar do aumento de exportadores de produtos florestais ao longo do período de análise, um número reduzido de competidores concentra frações cada vez maiores das exportações internacionais desses produtos; os índices sumários ( $H H I, E$ e $G$ ) indicaram que o aumento da competição e da concorrência não tem se traduzido em uma distribuição mais equitativa das exportações de produtos florestais, que levasse à redução das desigualdades e da concentração dos ganhos do setor; apesar da tendência decrescente dos $C R(4)$ e $C R(8)$, há uma elevação de $G$, isso porque os ganhos de escala do comércio internacional têm sido apropriado por poucos concorrentes; é recomendada cautela na análise dos índices sumários $(H H I, E$ e $G)$, que devem ser examinados em conjunto com os índices parciais $[C R(k)]$ para não tirar conclusões errôneas; os países com expressiva participação na pauta de exportações, como o Brasil, devem buscar estratégias comerciais para reter as vantagens competitivas conquistadas, principalmente aquelas advindas do ganho de escala.
\end{abstract}

Palavras-chave: economia florestal; concentração industrial; mercado internacional.

\begin{abstract}
This study analyzed the degree of concentration in worldwide exports of forest products in the period ranging from 1961 to 2008. The data used are available at the United Nations Food and Agriculture Organization (FAO). The concentration was determined by the concentration ratio $[H R(k)]$, the Herfindahl-Hirschman Index $(H H I)$, Theil Entropy Index $(E)$ and the Gini index $(G)$. The main conclusions were: The aggregate Brazilian share in the world exports of forest products is increasing over time; the most important sectors in the aggregate world exports of forest products, in decreasing order, were pulp, lumber, paper and cardboard, wooden panels, saw and fire wood. According to Bain, the concentration ratio of the four and eight largest exporters of forest products is moderately low; the HHI and Theil Entropy $(E)$ show a reduction in the concentration of world exports of forest products and greater competition among the countries that sell such products; the Gini index indicates that despite the increase in export of forest products over the period of analysis, a smaller number of competitors concentrate increasingly larger shares of international exports of

1 Economista, Professor, DSc. em Eng. Florestal - Universidade Federal da Paraíba/UFPB - Centro de Energias Alternativas e Renováveis/CEAR - Departamento de Engenharia de Energias Renováveis/DEER - Cx. Postal 5115, CEP 58.051-900 - João Pessoa/PB. E-mail: luiz@cear.ufpb.br

2 Engenheiro Florestal, PhD., Pesquisador Visitante do Departamento de Ciências Florestais, Universidade Federal de Lavras, Caixa Postal 3037, CEP 37200-000, Lavras (MG), Brasil. jlprezen@dcf.ufla.br

3 Engenheiro Florestal, Dr., Professor Associado IV do Departamento de Ciências Florestais, Universidade Federal de Lavras, Caixa Postal 3037, CEP 37200-000, Lavras (MG), Brasil. donizete@dcf.ufla.br

Recebido para publicação em 31/08/2010 e aceito em 22/06/2012
\end{abstract}


these products; summary indices (HHI, E and G) indicated that increased competition has not led to a more equitable distribution of forest products so as to bring down inequalities and concentration of profits in the sector; despite the downward trend in $C R(4)$ and $C R(8)$, there is an increase in G, probably because the economies of scale in the international trade have been held by few competitors; caution is recommended in the analysis of summary indices (HHI, $E$ and $G$ ) which had better be checked jointly with the partial indices $[C R(k)]$ in order to avoid wrong conclusions; countries with a significant share in total exports, such as Brazil, should seek business strategies to retain competitive advantages, especially those arising from economies of scale.

Keywords: forest economy; industrial concentration; international market.

\section{INTRODUÇÃO}

A força motriz da atividade florestal é a demanda dos seus diversos produtos. Segundo a FAO (2009), em 2006, o setor florestal mundial contribuiu com aproximadamente US\$ 468 bilhões ou 1\% do Produto Interno Bruto global. Juntos, os maiores países (Rússia, Canadá, China, Estados Unidos e Brasil) representaram mais de metade da área florestal do globo terrestre.

O crescimento externo de uma economia está associado com as estratégias de diversificação, principalmente em mercados pouco explorados, mas com potencial de crescimento, conjugada à própria necessidade de conseguir economias de escala e escopo (FEIJÓ et al., 2003).

Em um sentido amplo, entende-se "concentração industrial" como um processo que consiste no aumento do controle exercido pelas grandes empresas sobre a atividade econômica e é um dos componentes mais importantes da competição entre os países. Existe uma relação inversa entre concentração e concorrência, sendo que, à medida que se eleva a concentração, diminui o grau de competição entre os países, o que amplia o poder de mercado do país (POSSAS, 1999).

O poder de mercado configura-se na participação que um determinado país possui na produção ou vendas globais da indústria florestal. O cálculo dos índices de concentração disponibiliza os elementos empíricos necessários à análise da estrutura da indústria florestal e evidencia a dimensão da competitividade dos países exportadores florestais (POSSAS, 2002; RESENDE; BOFF, 2002).

Os países com maior extensão territorial, normalmente, apresentam vantagens comparativas em recursos naturais. Eles tendem a ser mais populosos e a ter maior participação no mercado de produtos primários. No entanto, alguns países e re- giões estão mais bem preparados para enfrentar os desafios e aproveitar as oportunidades que surgem, enquanto a outros ainda faltam condições institucionais, jurídicas e econômicas essenciais para gerir seus recursos florestais de forma sustentável.

As mudanças no mercado internacional, em curto prazo, podem influenciar na decisão individual das estratégias dos subsetores da indústria florestal, e, no longo prazo, têm a possibilidade de ter uma maior influência sobre os investimentos em plantios florestais e na indústria. Assim, o futuro da demanda global de produtos florestais estará vinculado à adoção de políticas ambientais e de energia sustentáveis, atreladas às mudanças demográficas, ao crescimento econômico e às questões regionais (FAO, 2009).

Os países que possuem vantagens comparativas e vantagens competitivas, normalmente, apresentam grande potencial de concentração industrial. Resende (1994) afirmou que a concentração sintetiza em um único indicador um conceito de múltiplas dimensões, como oferta e demanda, capacidade tecnológica, estrutura de custos, entre outros.

Há vários estudos sobre concentração industrial na atividade florestal, destacando-se o de Noce et al. (2005), referente ao mercado internacional de madeira serrada, Noce et al. (2007), para o mercado internacional de compensado, Noce et al. (2008), para o mercado internacional de aglomerado e os estudos de Braga e Mascolo (1982), Leite e Santana (1998), Hilgemberg e Bacha (2001), Montebello (2006) e Coelho Junior et al. (2010), para o setor de celulose e papel. Contudo, não há estudos mostrando a concentração do agregado do mercado mundial de produtos florestais.

O objetivo desse trabalho foi analisar o mercado mundial de produtos florestais e seu grau de concentração no período 1961- 2008, enfatizando o desempenho do Brasil. 


\section{MATERIAL E MÉTODOS}

\section{Dados utilizados}

Os dados utilizados na mensuração da concentração das exportações florestais para o período 1961- 2008 foram obtidos da FAO (Organização das Nações Unidas para Agricultura e Alimento). A FAO, em seus dados estatísticos, só considera os países que tiveram o valor das exportações de produtos florestais superiores a mil dólares americanos (X > US\$1.000,00). O agregado dos produtos florestais é composto pelo somatório de todas as exportações de produtos florestais definidos pela FAO (2010).

\section{O mercado internacional dos produtos florestais}

Para a leitura da análise do mercado internacional de produtos florestais foram realizados três cortes temporais: de 1961 a 1990 - período da Guerra Fria; de 1991 a 2000 - final do século XX e início do processo de globalização; de 2001 a 2008 - século XXI.

Para o estudo do mercado internacional de produtos florestais, em 2008 consideraram-se os dez maiores exportadores, no agregado. Além destes, foram considerados, ainda, Itália, Chile, Malásia, Portugal, Noruega e África do Sul, por terem sido aqueles que mais ganharam posição entre os maiores exportadores mundiais no período analisado.

\section{Medidas de concentração e de desigualdade}

As medidas de concentração podem ser classificadas como parciais ou sumárias. Os índices parciais consideram apenas a parte dos países que atua em certa indústria. Já os índices sumários utilizam dados de todos os países que atuam no mercado.

As razões de concentração são consideradas os exemplos mais importantes de índices parciais. Já os Índices de Hirschman-Herfindal e Entropia de Theil são os que melhor representam os índices sumários. Além desses índices de concentração, existe ainda o Índice de Gini que é uma medida utilizada para medir a desigualdade, principalmente da renda, mas que pode também ser usado para medir a diferença entre o tamanho e o poder econômico dos países. Os índices usados nesse trabalho são caracterizados a seguir.

\section{Razão de Concentração}

Esse índice considera a participação no mercado internacional dos $k$ (sendo $k=1,2, \ldots, n$ ) países maiores exportadores de determinado produto ou agregado de produtos. Bain (1959) diz que a forma algébrica da Razão de Concentração é:

$$
C R(k)=\sum_{i=1}^{k} s_{i}
$$

Em que,

$C R(k)=$ Razão de Concentração de $k$ países exportadores de produtos florestais;

$s_{i}=$ market share, em porcentagem, do país $i$ para o valor das exportações de produtos florestais.

Convencionalmente, utiliza-se o $C R(4)$ e o $C R(8)$ para análise de concentração industrial, pois, na medida em que o valor do índice aumenta, eleva-se também o poder de mercado virtual dos países maiores exportadores. A Tabela 1 ilustra os diferentes níveis de concentração e as respectivas classificações para $C R(4)$ e $C R(8)$. Para o cálculo da razão

TABELA 1: Classificação do grau de concentração dos maiores países exportadores.

TABLE 1: Concentration rank of major exporting countries.

\begin{tabular}{ccc}
\hline Grau de Concentração & $C R(4)$ & $C R(8)$ \\
\hline Muito Alto & $75 \%$ ou mais & $90 \%$ ou mais \\
Alto & $65 \%-75 \%$ & $85 \%-90 \%$ \\
Moderadamente Alto & $50 \%-65 \%$ & $70 \%-85 \%$ \\
Moderadamente Baixo & $35 \%-50 \%$ & $45 \%-70 \%$ \\
Baixo & $35 \%$ ou menos & $45 \%$ ou menos \\
\hline
\end{tabular}

Fonte: Bain (1959). 
de concentração, as participações dos países foram ordenadas de forma decrescente.

\section{Índice de Herfindahl-Hirschman}

O Índice Herfindahl-Hirschman (HHI), também conhecido como Índice Herfindahl, é uma ferramenta de análise de concentração de mercado proposta de forma independente por Hirschman (1945) e Herfindahl (1950). Em 1964, Hirschman (1964) publicou a obra "The Paternity of an Index" que reivindica a posse original do índice.

O HHI mede a concentração industrial utilizando os dados de todos os países, em dada indústria, por meio da expressão:

$$
H H I=\sum_{i=1}^{n} s_{i}^{2}
$$

Em que,

$n$ = número de nações que exportam produtos florestais;

$s_{i}=$ market share, em porcentagem, do país $i$ para o valor das exportações de produtos florestais.

O HHI evidencia os pesos relativos da participação de cada país. Ao se elevar ao quadrado o market share dos países, atribui-se um maior peso aos que têm maior participação. Segundo Resende (1994), o limite inferior do índice é $1 / n$, situação em que todos os países têm o mesmo tamanho. Já o limite superior do índice é igual a 1, indicando haver uma concentração máxima, quando há uma situação de monopólio.

Para o uso de análises comparativas, quando ocorre uma variação no número de países em dada indústria, Resende (1994) sugeriu um ajuste na fórmula do $H H I$, da seguinte forma:

$$
H H I^{\prime}=\frac{1}{n-1}(n H H I-1) ; n>1
$$

A utilização dessa equação implica em um intervalo de variação entre 0 e 1 para o $H H I$. Assim, à medida que o índice se afasta de zero, maior será a concentração. Ou seja, um índice $H H<0,1$ indica um mercado altamente competitivo. Um índice no intervalo $H H<0,15$ indica um mercado não concentrado. Um índice no intervalo $0,15 \leq H H \leq$ 0,25 indica concentração moderada. $\mathrm{E}$, um índice $H H>0,25$ indica alta concentração.

\section{Índice de Entropia de Theil $(E)$}

Proposto por Theil (1967), o Índice de Entropia foi originalmente formulado para se verificar o conteúdo informacional da mensagem que as firmas transmitiriam, dado o grau de surpresa que as mesmas teriam, diante de certo evento. $\mathrm{O}$ índice, porém, pode ser aplicado à economia industrial para medir a concentração das exportações de qualquer setor.

A fórmula matemática utilizada para o cálculo da Entropia $(E)$ é:

$$
E=-\sum_{i=1}^{n} \ln \left(s_{i}\right)
$$

Em que,

$n=\mathrm{n}^{\mathrm{o}}$ de nações participantes nas exportações mundiais de produtos florestais;

$s_{i}=$ market share do país $i$ para o valor das exportações mundiais de produtos florestais;

$\ln =$ logaritmo neperiano.

O índice de Entropia mede o inverso da concentração. Quanto menor o valor do índice mais concentrada são as exportações mundiais. Um número maior de empresas implica em um valor mais elevado da Entropia, dependendo do quão desigual é o tamanho das mesmas. Em situações de monopólio, o valor da Entropia é igual a zero, o que significa concentração máxima. Já o limite superior do índice é igual a $\ln (n)$, isto é, as empresas possuem parcelas iguais de mercado e concentração mínima (RESENDE; BOFF, 2002).

De forma análoga ao sugerido para o $H H I$, Resende (1994) indicou que, para análises intertemporais, a expressão para o cálculo da Entropia fosse ajustada da seguinte forma:

$$
E^{\prime}=-\frac{1}{\ln (n)} \sum_{i=1}^{n} s_{i} \ln \left(s_{i}\right)
$$

Assim, a Entropia passa a variar entre 0, monopólio (concentração máxima), e 1, concorrência perfeita (concentração mínima).

\section{Coeficiente de Gini $(G)$}

O Coeficiente de Gini $(G)$ é uma medida de desigualdade desenvolvida por Gini (1912) na obra "Variabilità e mutabilità". Este coeficiente, origi- 
nalmente formulado para medir a desigualdade de renda pode, também, ser usado para medir o grau de desigualdade das exportações de produtos florestais dos países. O índice é uma ferramenta acessória aos coeficientes de concentração, uma vez que uma concentração elevada implica em uma desigualdade maior.

O cálculo do índice é feito utilizando-se a seguinte expressão,

$$
G=1-\frac{\left[\sum_{i=1}^{n}\left(s_{i j}+s_{i}\right)\right]}{n}
$$

Sendo,

$n=$ número de países exportadores de produtos florestais;

$s_{i j}=$ participação cumulativa das exportações mundiais de produtos florestais em ordem crescente;

$s_{i}=$ market share, em porcentagem, do país $i$ para o valor das exportações mundiais de produtos florestais.

O índice varia entre 0 e 1 , classificado da seguinte forma: $0,101-0,250$ desigualdade nula a fraca; 0,251-0,500 desigualdade fraca a média; $0,501-0,700$ desigualdade média a forte; 0,701
- 0,900 desigualdade forte a muito forte; $0,900-$ 1,000 desigualdade muito forte a absoluta.

\section{RESULTADOS E DISCUSSÃO}

\section{O mercado internacional dos produtos florestais}

A análise do mercado internacional de produtos florestais foi realizada em três cortes temporais: de 1961 a 1990 - período da Guerra Fria; de 1991 a 2000 - final do século XX e início do processo de globalização; de 2001 a 2008 - século XXI.

Segundo os registros da FAO (2010), em 1961 as vendas de produtos florestais no mercado internacional totalizaram US\$ 5,16 bilhões, sendo que 104 países participaram desse comércio. Até 1989 a quantidade de países exportadores oscilou pouco, chegando nesse ano a 112.

No período 1961-1989, as exportações mundiais cresceram a uma taxa média de $10 \%$ ao ano. Em 1990 o valor total das exportações mundiais de produtos florestais foi de US\$104,5 bilhões. O rápido crescimento das exportações brasileiras de celulose, entre 1961 a 1980, possivelmente causado pelo Programa Nacional de Papel e Celulose, explica o ganho de posicionamento do país no ranking dos maiores exportadores de produtos florestais.

TABELA 2: Evolução do ranking dos países exportadores de produtos florestais (1961-2008).

TABLE 2: Evolution in the ranking of countries exporting forest products (1961-2008).

\begin{tabular}{ccccccccccccc}
\hline Países & 1961 & 1966 & 1971 & 1976 & 1981 & 1986 & 1991 & 1996 & 2001 & 2006 & 2007 & 2008 \\
\hline Canadá & 1 & 1 & 1 & 1 & 1 & 1 & 1 & 1 & 1 & 1 & 1 & 1 \\
Alemanha & 10 & 10 & 6 & 6 & 6 & 5 & 5 & 5 & 4 & 3 & 2 & 2 \\
Estados Unidos & 4 & 2 & 3 & 2 & 2 & 2 & 2 & 2 & 2 & 2 & 3 & 3 \\
Suécia & 3 & 3 & 2 & 3 & 3 & 3 & 3 & 3 & 5 & 4 & 4 & 4 \\
Finlândia & 2 & 4 & 4 & 4 & 4 & 4 & 4 & 4 & 3 & 5 & 5 & 5 \\
Rússia & - & - & - & - & - & - & - & 11 & 9 & 7 & 6 & 6 \\
China & 25 & 21 & 14 & 18 & 18 & 19 & 14 & 10 & 10 & 6 & 7 & 7 \\
França & 7 & 7 & 8 & 10 & 9 & 7 & 7 & 9 & 6 & 8 & 8 & 8 \\
Áustria & 6 & 6 & 7 & 8 & 8 & 8 & 8 & 8 & 8 & 9 & 9 & 9 \\
Brasil & 19 & 20 & 21 & 28 & 11 & 12 & 17 & 14 & 12 & 12 & 10 & 10 \\
Itália & 24 & 17 & 17 & 16 & 17 & 14 & 13 & 13 & 15 & 13 & 13 & 13 \\
Chile & 38 & 38 & 33 & 30 & 27 & 26 & 23 & 20 & 19 & 17 & 16 & 15 \\
Malásia & 15 & 12 & 9 & 7 & 7 & 10 & 9 & 7 & 13 & 14 & 17 & 17 \\
Portugal & 29 & 31 & 26 & 25 & 26 & 18 & 20 & 22 & 24 & 21 & 21 & 21 \\
Noruega & 8 & 8 & 10 & 11 & 15 & 13 & 18 & 16 & 18 & 24 & 25 & 25 \\
África do Sul & 27 & 28 & 28 & 32 & 33 & 22 & 31 & 24 & 27 & 29 & 31 & 30 \\
\hline
\end{tabular}


No período 1991-2000, as exportações cresceram a taxa anual de $3,94 \%$, partindo de US\$ 98,22 bilhões e chegando a US\$ 144,61 bilhões. O número de países exportadores de produtos florestais saltou de 112 para 183 , o que tornou o mercado internacional mais competitivo. No período 20012008 , as exportações cresceram a taxa anual de $7,6 \%$ e o valor das exportações ultrapassou os US\$ 200 bilhões.

A Tabela 2 apresenta o ranking dos maiores exportadores de produtos florestais, no período 1961-2008. A hegemonia é do Canadá, que se manteve como o maior exportador em todo o período analisado. Os Estados Unidos se mantiveram em segundo lugar por vários anos, mas, recentemente (2007 e 2008), perderam essa posição para a Alemanha.

A União Soviética ocupou o $5^{\circ}$ lugar, de 1961 a 1983 , chegando ao $10^{\circ}$ lugar do ranking em 1991. A Rússia foi quem deteve a maior participação das exportações florestais após o desmembramento da União Soviética. Em 1992, ocupou a $17^{\text {a }}$ posição e, no ano seguinte, recuperou-se, elevando- -se no ranking para o $9^{\circ}$ lugar e permaneceu entre os dez maiores exportadores daí para frente. Em 2008, a Rússia situou-se na sexta colocação no mercado mundial de produtos florestais.

No período 1961-2008, os países que mais ganharam posições no ranking mundial foram Chile $\left(38^{\circ} \rightarrow 15^{\circ}\right)$, China $\left(25^{\circ} \rightarrow 7^{\circ}\right)$, Itália $\left(24^{\circ}\right.$ $\left.\rightarrow 13^{\circ}\right)$, Brasil $\left(19^{\circ} \rightarrow 10^{\circ}\right)$ e Alemanha $\left(10^{\circ} \rightarrow 2^{\circ}\right)$.

Os Estados Unidos, a Suécia e a França permaneceram estagnados entre os maiores exportadores e perderam apenas uma posição no ranking. Já Noruega, Áustria e Finlândia, foram os países que mais perderam posições no mercado internacional de produtos florestais.

Os países que agregaram valor aos produtos florestais exportados, principalmente, PMVA (produtos de maior valor agregado) foram aqueles que melhoraram seu posicionamento no ranking mundial.

Em 2008, o valor das exportações mundiais de produtos florestais atingiu US\$ 235,12 bilhões (Tabela 3). O market share dos países da Tabela 3 representou $71,83 \%$ do valor total das exportações

TABELA 3: Ranking dos países maiores exportadores das principais commodities de produtos florestais, em 2008 (Milhões de US\$).

TABLE 3: Ranking of countries of major commodity exports of forest products in 2008 (Million U.S. \$).

\begin{tabular}{ccccccccc}
\hline País & $\begin{array}{c}\text { Madeira } \\
\text { para fins } \\
\text { industriais }\end{array}$ & Energia & Celulose & $\begin{array}{c}\text { Papel e } \\
\text { papelão }\end{array}$ & $\begin{array}{c}\text { Madeira } \\
\text { serrada }\end{array}$ & $\begin{array}{c}\text { Painéis de } \\
\text { Madeira }\end{array}$ & Outros & Total \\
\hline Canadá & 300,79 & 5,82 & $6.589,55$ & $8.814,77$ & $5.059,40$ & $3.685,98$ & 482,93 & $24.939,24$ \\
Alemanha & 725,98 & 6,02 & 720,80 & $14.422,46$ & $2.592,06$ & $4.103,37$ & 870,35 & $23.441,03$ \\
EUA & $1.643,07$ & 11,44 & $4.607,86$ & $9.838,48$ & $1.715,08$ & $1.129,36$ & $3.515,15$ & $22.460,43$ \\
Suécia & 218,60 & 9,27 & $2.689,54$ & $10.406,10$ & $3.419,54$ & 267,28 & 154,66 & $17.164,99$ \\
Finlândia & 99,24 & 1,02 & $1.554,26$ & $10.759,33$ & $1.697,70$ & $1.010,74$ & 81,26 & $15.203,55$ \\
Rússia & $3.497,58$ & 13,65 & $1.152,10$ & $1.802,95$ & $2.829,28$ & $1.081,08$ & 241,16 & $10.617,81$ \\
China & 137,23 & 0,44 & 19,38 & $3.831,51$ & 517,64 & $5.018,40$ & 189,29 & $9.713,88$ \\
França & 347,69 & 20,60 & 350,44 & $5.535,87$ & 435,53 & $1.170,80$ & 540,98 & $8.401,91$ \\
Áustria & 116,77 & 3,41 & 215,51 & $4.130,09$ & $1.913,19$ & $1.713,13$ & 211,17 & $8.303,27$ \\
Brasil & 9,29 & 0,00 & $3.904,44$ & $2.364,38$ & 675,06 & 798,32 & 164,27 & $7.915,76$ \\
Itália & 10,82 & 0,14 & 31,89 & $4.520,71$ & 192,03 & 688,27 & 264,56 & $5.708,41$ \\
Chile & 5,50 & 0,00 & $2.625,71$ & 472,58 & 740,41 & 694,45 & 334,23 & $4.872,89$ \\
Malásia & 420,18 & 2,57 & 4,45 & 300,12 & 909,69 & $2.122,84$ & 64,90 & $3.824,74$ \\
Portugal & 158,66 & 2,35 & 635,43 & $1.327,06$ & 92,33 & 336,96 & 106,68 & $2.659,45$ \\
Noruega & 66,51 & 0,15 & 513,27 & $1.227,27$ & 105,71 & 110,81 & 53,97 & $2.077,68$ \\
África do Sul & 16,30 & 0,00 & 524,13 & 663,29 & 11,96 & 47,45 & 329,73 & $1.592,86$ \\
\hline Total & $7.774,20$ & 76,87 & $26.138,73$ & $80.416,96$ & $22.906,61$ & $23.979,22$ & 7605,29 & $168.897,90$ \\
Resto do mundo & $4.944,30$ & 203,61 & $5.608,83$ & $29.334,40$ & $7.654,20$ & $11.825,59$ & $6.655,78$ & $66.226,70$ \\
Mundo & $12.718,50$ & 280,48 & $31.747,56$ & $109.751,36$ & $30.560,81$ & $35.804,81$ & $14.261,07$ & $235.124,59$ \\
\hline
\end{tabular}


mundiais de produtos florestais. Observa-se que, na medida em que a economia de escala se eleva a concentração aumenta, devido a ganhos proporcionados pelo progresso tecnológico. O segmento florestal que se apresenta com exportações mais significativas no agregado é a indústria de celulose com $82,33 \%$ do total, seguida da madeira serrada $(74,95 \%)$, papel e papelão $(73,27 \%)$, painéis de madeira $(66,97 \%)$, madeira para fins industriais $(61,12 \%)$ e energia $(27,41 \%)$.

O agregado "papel e papelão" foi o bem que gerou o maior montante de recursos em relação ao total mundial $(46,68 \%)$, sendo que os principais países exportadores são Alemanha, Finlândia, Suécia, Estados Unidos e Canadá. A seguir vêm os painéis de madeira $(15,23 \%)$ e a celulose $(13,5 \%)$.

Entre os países que compõem o BRIC (Brasil, Rússia, Índia e China), apenas a Índia não se situa entre os 10 maiores exportadores de produtos florestais. Ela se encontra na $48^{\circ}$ posição no ranking mundial. Em 2008, o valor das exportações de produtos florestais do BRIC foi de US\$ 28,69 bilhões, correspondendo a $12,2 \%$ do total mundial. A participação dos produtos florestais foi: $28,98 \%$ papel e papelão, $24,28 \%$ painéis de madeira, $17,73 \%$ celulose, $12,70 \%$ madeira para fins industriais, $14,14 \%$ madeira serrada, $0,05 \%$ energia e $2,10 \%$ outros.

Em 2008, o Brasil situava-se em $10^{\circ}$ lugar no ranking mundial, dos exportadores de produtos florestais, sendo sua maior participação no segmento de papel e papelão $(7,74 \%)$, seguido por painéis de madeira $(5,60 \%)$, celulose $(3,56 \%)$, madeira para fins industriais $(3,31 \%)$ e madeira serrada $(1,89 \%)$.

\section{Medidas de concentração e de desigualdade}

Os resultados obtidos referem-se à concentração do mercado internacional como um todo, não considerando o destino das exportações de produtos florestais.

\section{Razão da concentração das exportações florestais}

A Figura 1 apresenta as razões de concentração dos países maiores exportadores de produtos florestais. Ao longo do período de análise, os países que representaram o $C R(4)$ foram, praticamente, o Canadá, os Estados Unidos, a Suécia e a Finlândia. Para Scherer e Ross (1990), quando os quatro países maiores exportadores detêm mais de $40 \%$ do mercado de determinado produto, a estrutura desse mer- cado é oligopolística. Assim, no período 1961-2005, a indústria florestal apresentou uma estrutura de mercado com concentração moderada. Entretanto, a partir de 2006 ela perdeu essa condição e iniciou uma caminhada em direção a uma situação de mercado mais competitivo.

Seguindo as orientações de Bain (1959), para avaliar a concentração dos quatro maiores [CR(4)] exportadores de produtores florestais, observou-se que o índice variou de $37,15 \%$ a $57,15 \%$, com média de $50,05 \%$, indicando um grau de concentração moderadamente alto (Tabela 1). No período 1961-2007 observou-se uma tendência de redução da concentração das exportações de produtos florestais.

De 1961 a 1990, o grau de concentração foi moderadamente alto, já que esteve entre o intervalo de $50,28 \%$ e $57,41 \%$, com uma tendência decrescente ao longo do tempo. Após a década de 90, a concentração passou a ser moderadamente baixa, com uma maior competição entre os países, chegando a uma $C R(4)$ de $37,43 \%$ em 2008 . A projeção para os próximos 5 anos é que se chegue a uma concentração ainda mais baixa, isto é, a um mercado mais competitivo.

No período 1961-2007, a concentração dos oito países que mais exportam produtos florestais $[C R(8)]$ variou na faixa de $56,12 \%$ a $73,58 \%$, com média de $67,08 \%$, caracterizando uma concentração moderadamente baixa (Tabela 1), na maioria dos anos analisados. A partir de 1984, a concentração

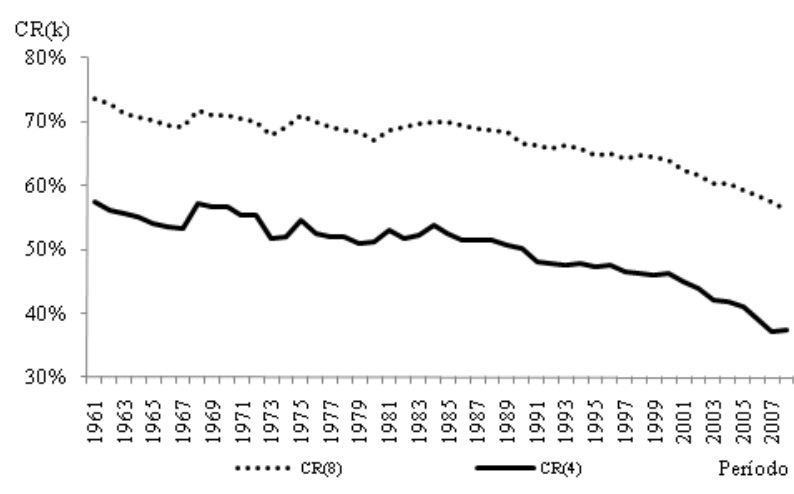

FIGURA 1: Desenvolvimento da Razão de Concentração dos países maiores exportadores de produtos florestais (1961 - 2008).

FIGURE 1: Evolution of the concentration ratio of the largest exporters of forest products (1961 - 2008). 
passa a ser moderadamente baixa, uma vez que os valores obtidos foram inferiores a $70 \%$. Em alguns anos, os índices $C R(4)$ e $C R(8)$, apresentam trajetórias distintas. Em 2008, o índice $C R(4)$ se eleva, mas o índice $C R(8)$ se reduz. De forma geral, esses movimentos distintos dos referidos índices estão associados às oscilações das exportações dos quatro e dos oito maiores países.

\section{Concentração segundo os índices $\mathrm{HHI}$ e $\mathrm{HHI}$ '}

A Figura 2 apresenta os Índices $H H I$ e $H H I$ ' dos países cujas exportações tiveram valores superiores a US\$1.000,00. No período analisado há uma tendência de desconcentração, já que os índices foram decrescentes até o ano de 2008.

$\mathrm{O}$ valor do $H H$ aproxima-se gradualmente da situação de heterogeneidade do mercado - limite inferior. A concentração medida pelo HHI' também apresentou decréscimo no período considerado.

Deve-se observar que, no total das exportações mundiais, segundo a metodologia da FAO, não se consideraram os países cujas exportações não atingem US\$1.000,00 anuais, diminuindo o número de países da relação, consequentemente, afetando os índices sumários de concentração usados no estudo.

Segundo as classificações do $H H I$, as exportações mundiais de produtos florestais apresentam em um mercado não concentrado, com $H H I<$ 0,15. Apenas na década de 1960 indicaram, em anos específicos, que o mercado não é altamente competitivo, com $H H I<0,10$.

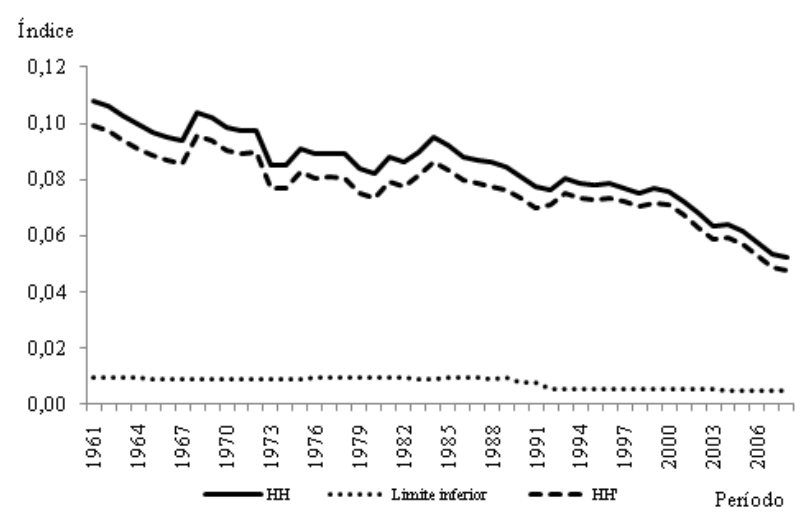

FIGURA 2: Índices $H H$, limite inferior do $H H$, $H H I$ ' dos países exportadores de produtos florestais (1961 - 2008).

FIGURE 2: $H H$ Index, lower boundary of HHI,HHI' set of countries exporting forest products (1961 - 2008).

\section{Concentração segundo o índice de Entropia de Theil}

A Tabela 4 apresenta os índices de Entropia das exportações de produtos florestais. Entre 1961 a 1989, há pouca variação no número de países, porém, a concentração diminui principalmente devido ao crescimento do market share dos países com vocação florestal (Ex. Brasil e Chile), onde ocorreram ganhos tecnológicos via incentivos de políticas públicas.

O limite superior apresentou valor mínimo de 46,444, em 1961, valor máximo de 52,832, em 2008 e gerou uma média ao longo do período analisado de 48,896. No período 1991-92 houve o deslocamento da curva do limite superior devido à expansão dos países exportadores de produtos florestais. A FAO registrou 126 países, em 1991, que passou para 190 países exportadores no ano seguinte. Este fenômeno se dá em grande parte por causa do desmembramento da União Soviética. Enquanto o limite superior se deslocou, neste período o índice de Entropia $(E)$ permaneceu estável fazendo com que a diferença entre as curvas aumentasse, proporcionando o aumento da concentração.

Segundo o índice de Entropia ajustado ( $\left.E^{\prime}\right)$, em todo período analisado, a maior concentração foi no ano de 1993, em que houve maior diferença entre o índice de Entropia e o limite superior. Se, à medida que a Entropia se aproxima de seu limite superior, a concentração diminui, observa-se que a concentração, a partir de 2008, é menos elevada que aquela observada em 2000. Esta diminuição pode ser verificada nos resultados da Entropia ajustada paras os referidos anos. Os níveis de concentração de 2008 são parecidos com os dos anos de 1974 e 1978, intervalo no qual ocorreu a menor concentração das exportações mundiais de produtos florestais.

\section{Desigualdade das exportações de produtos florestais segundo o coeficiente de Gini}

À medida que os valores do coeficiente de Gini se aproximam de 1, a desigualdade nas exportações de produtos florestais aumenta. A Figura 3 indica que a desigualdade nas exportações de produtos florestais aumentou ao longo do período analisado, ou seja, sua classificação é de uma desigualdade muito forte a absoluta $(0,9-1,0)$.

Em 1961, o índice foi de 0,9188, quando se considerou 104 países exportadores de produtos florestais. No período 1960-1990, o índice de Gini mé- 
TABELA 4: Índice de Entropia $(E)$, limite superior de $E$, índice de Entropia ajustado $(E ')$ e número de países (1961 - 2008).

TABLE 4: Entropy Index $(E)$, upper boundary of $E$, adjusted Entropy index $\left(E^{\prime}\right)$, number of countries (1961 - 2008).

\begin{tabular}{|c|c|c|c|c|}
\hline Anos & $E$ & Limite superior & $E^{\prime}$ & no países \\
\hline 1961 & 28,336 & 46,444 & 0,6101 & 104 \\
\hline 1962 & 28,488 & 46,444 & 0,6134 & 104 \\
\hline 1963 & 28,779 & 46,444 & 0,6197 & 104 \\
\hline 1964 & 29,139 & 46,821 & 0,6223 & 108 \\
\hline 1965 & 29,321 & 47,185 & 0,6214 & 112 \\
\hline 1966 & 29,476 & 46,913 & 0,6283 & 109 \\
\hline 1967 & 29,538 & 47,005 & 0,6284 & 110 \\
\hline 1968 & 28,759 & 47,095 & 0,6107 & 111 \\
\hline 1969 & 29,029 & 47,185 & 0,6152 & 112 \\
\hline 1970 & 29,074 & 47,005 & 0,6185 & 110 \\
\hline 1971 & 29,317 & 47,185 & 0,6213 & 112 \\
\hline 1972 & 29,392 & 47,274 & 0,6217 & 113 \\
\hline 1973 & 30,197 & 47,185 & 0,6400 & 112 \\
\hline 1974 & 29,989 & 47,005 & 0,6380 & 110 \\
\hline 1975 & 29,448 & 47,005 & 0,6265 & 110 \\
\hline 1976 & 29,682 & 46,821 & 0,6340 & 108 \\
\hline 1977 & 29,782 & 46,821 & 0,6361 & 108 \\
\hline 1978 & 29,873 & 46,540 & 0,6419 & 105 \\
\hline 1979 & 30,117 & 46,821 & 0,6432 & 108 \\
\hline 1980 & 30,365 & 46,540 & 0,6525 & 105 \\
\hline 1981 & 29,942 & 46,821 & 0,6395 & 108 \\
\hline 1982 & 30,063 & 46,821 & 0,6421 & 108 \\
\hline 1983 & 29,750 & 46,913 & 0,6342 & 109 \\
\hline 1984 & 29,422 & 46,913 & 0,6272 & 109 \\
\hline 1985 & 29,530 & 46,728 & 0,6320 & 107 \\
\hline 1986 & 29,590 & 46,728 & 0,6332 & 107 \\
\hline 1987 & 29,675 & 46,821 & 0,6338 & 108 \\
\hline 1988 & 29,677 & 46,913 & 0,6326 & 109 \\
\hline 1989 & 29,783 & 46,821 & 0,6361 & 108 \\
\hline 1990 & 30,163 & 48,598 & 0,6207 & 129 \\
\hline 1991 & 30,432 & 48,363 & 0,6292 & 126 \\
\hline 1992 & 31,054 & 52,470 & 0,5918 & 190 \\
\hline 1993 & 30,711 & 52,040 & 0,5901 & 182 \\
\hline 1994 & 31,077 & 52,311 & 0,5941 & 187 \\
\hline 1995 & 31,012 & 52,257 & 0,5935 & 186 \\
\hline 1996 & 31,094 & 52,257 & 0,5950 & 186 \\
\hline 1997 & 31,413 & 52,095 & 0,6030 & 183 \\
\hline 1998 & 31,437 & 52,311 & 0,6010 & 187 \\
\hline 1999 & 31,425 & 51,985 & 0,6045 & 181 \\
\hline 2000 & 31,564 & 52,095 & 0,6059 & 183 \\
\hline 2001 & 32,085 & 52,204 & 0,6146 & 185 \\
\hline 2002 & 32,407 & 52,364 & 0,6189 & 188 \\
\hline 2003 & 32,785 & 52,523 & 0,6242 & 191 \\
\hline 2004 & 32,823 & 52,730 & 0,6225 & 195 \\
\hline 2005 & 32,998 & 52,730 & 0,6258 & 195 \\
\hline 2006 & 33,231 & 52,781 & 0,6296 & 196 \\
\hline 2007 & 33,568 & 52,832 & 0,6354 & 197 \\
\hline 2008 & 33,904 & 52,832 & 0,6417 & 197 \\
\hline
\end{tabular}




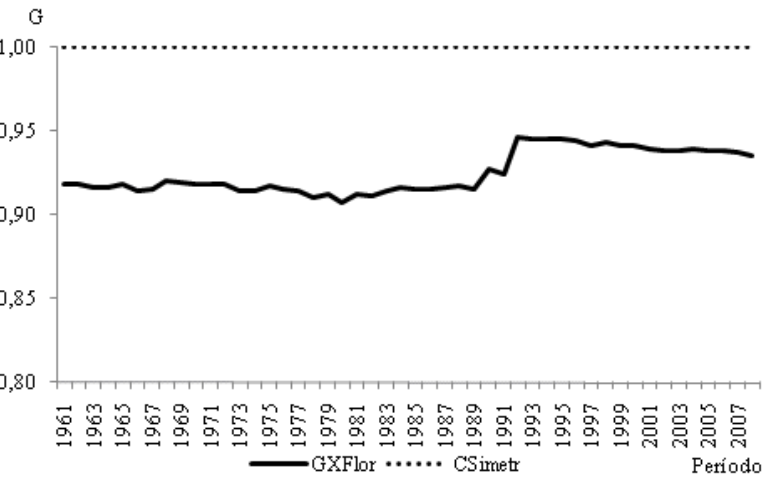

FIGURA 3: O desenvolvimento do coeficiente de Gini nas exportações mundiais de produtos florestais (GXFlor) e a curva de simetria (CSimetr), ao longo do tempo (1961 - 2008).

FIGURE 3: The development of the Gini Index of world exports of forest products (GXFlor) and the curve of symmetry (CSimetr) over time (1961 - 2008).

dio foi de 0,91578 , mas houve pequenas variações em relação à média. $\mathrm{O}$ índice mais elevado no período foi em 1968 com $G=0,9202$ para 111 países. A partir desse ano até 1980 , a tendência foi de desigualdade menos forte, chegando a um índice de 0,9074, para 105 países.

O fim da Guerra Fria, no final da década de 80 , foi o ponto de partida do processo de globalização da economia mundial. No início deste processo, entre 1991 e 1993, ocorreu um deslocamento abrupto nos valores do índice de Gini, elevando-se de 0,9242, em 1991, para 0,9454 em 1993, devido a um número reduzido de competidores o que concentrou frações cada vez maiores do market share.

Com o desmembramento da União Soviética e a instituição da CEI (Comunidade dos Estados Independentes) houve um acréscimo no número de países exportadores de produtos florestais no mercado internacional, que se elevou de 126 para 182 países, respectivamente, proporcionando um mercado mais competitivo, mas a desigualdade entre os países ficou ainda mais forte.

No período 1993-2008 ampliou-se o número de competidores em $0,58 \%$ a.a. nas exportações internacionais de produtos florestais, chegando a 197 países. Consequentemente, indicou a redução de $\mathrm{G}$ em $6,47 \%$ a.a., no mesmo período, concentrando em frações cada vez menores do market share, diminuído assim a desigualdade entre os países.

\section{CONCLUSÕES}

A participação brasileira nas exportações mundiais do agregado de produtos florestais é crescente ao longo do tempo;

Os setores mais significativos do agregado das exportações mundiais de produtos florestais, em ordem decrescente, foram os segmentos de celulose, madeira serrada, papel e papelão, painéis de madeira, madeira para fins industriais e madeira para energia;

Segundo a classificação de Bain, a Razão de Concentração dos quatro e oito maiores exportadores de produtos florestais é moderadamente baixa;

Os indicadores $H H I$ e $E$ assinalam movimentos descendentes para uma menor concentração das exportações mundiais de produtos florestais e maior competição entre os países que comercializam tais produtos;

O índice de Gini indica que, apesar do aumento de exportadores de produtos florestais ao longo do período de análise, apenas um número reduzido de competidores concentra frações cada vez maiores das exportações internacionais de produtos florestais;

Os índices sumários ( $H H I, E$ e $G)$ indicaram que o aumento da competição e da concorrência não se tem traduzido em uma distribuição mais equitativa das exportações de produtos florestais, com redução das desigualdades e da concentração dos ganhos do setor;

Apesar da tendência decrescente dos $C R(4)$ e $C R(8)$, há uma elevação de $G$, isso porque os ganhos de escala do comércio internacional têm sido dissipados em favor de uns poucos concorrentes, superiores aos índices parciais estudados;

É recomendada cautela na análise dos índices sumários (HHI, E e $G$ ) e que a análise dos mesmos seja feita em conjunto com os índices parciais $[C R(k)]$ para se evitar conclusões errôneas;

Os países com expressiva participação na pauta de exportações, como o Brasil, devem buscar estratégias comerciais para reter as vantagens competitivas conquistadas, principalmente aquelas advindas do ganho de escala.

\section{REFERÊNCIAS BIBLIOGRAFICAS}

BAIN, J. Industrial organization. New York: J. Wiley, 1959. $274 \mathrm{p}$.

BRAGA, H. C.; MASCOLO, J. L. Mensuração da concentração industrial no Brasil. Revista Pesquisa 
e Planejamento Econômico, Rio de Janeiro, v. 12, n. 2, p. 399-454, ago. 1982.

COELHO JUNIOR, L. M. et al. Analysis of the brazilian cellulose industry concentration (1998 a 2007). Cerne, Lavras, v.16, n. 2, p. 209-216, abr./ jun. 2010.

FEIJO, C. A.; CARVALHO, P. G. M.; RODRIGUEZ, M. S. Concentração industrial e produtividade do trabalho na indústria de transformação nos anos 90 : evidências empíricas. Economia, Niterói, v. 4, n. 1, p. 19-52, jan./jun. 2003

FOOD AND AGRICULTURE ORGANIZATION OF THE UNITED NATIONS. FAO Statistics Division 2010. Rome, 2010. Disponível em: http:// faostat.fao.org/ site/626/default.aspx\#ancor. Acesso em: 10 fev. 2010.

FOOD AND AGRICULTURE ORGANIZATION OF THE UNITED NATIONS. State of the world's forests. Rome, 2009. 152 p.

FOOD AND AGRICULTURE ORGANIZATION OF THE UNITED NATIONS. State of the world's forests. Rome, 2007. 144 p.

GINI, C. Variabilità e mutabilità (1912). In: PIZETTI, E.; SALVEMINI, T. (Ed.). Reprinted in memorie di metodologica statistica. Rome: Libreria Eredi Virgilio Veschi, 1955.

HERFINDAHL, O. C. Concentration in the Steel Industry. 1950. $175 \mathrm{f}$. Thesis (Ph.D.) - Columbia University, New York, 1950.

HILGEMBERG, E. M.; BACHA, C. J. C. A evolução da indústria brasileira de celulose e sua atuação no mercado mundial. Revista Análise Econômica, Porto Alegre, v. 19, n. 36, p.145-164, set. 2001.

HIRSCHMAN, A. O. National power and the structure of foreign trade. Berkley: University of California, 1945. $172 \mathrm{p}$.

HIRSCHMAN, A. O. The paternity of an index. The American Economic Review, Pittsburgh, v. 54, n. 5, p 761-762, Sept. 1964.

LEITE, A. L. S.; SANTANA, E. A. Índices de Concentração na indústria de papel e celulose. In: ENCONTRO NACIONAL DE ENGENHARIA DE
PRODUÇÃO, 1998, Niterói. Anais... Niterói: UFF, 1998. 1 CD-ROM.

LERDA, J. C. Globalização da economia e perda de autonomia das autoridades fiscais, bancárias e monetárias. In: BAUMANN, R. (Org.). O Brasil e a Economia Global. Rio de Janeiro: Campus, 1996. cap. 12 , p. 239-263.

MONTEBELLO, A. E. S. Análise da evolução da indústria brasileira de celulose no período de 1980 a 2005. 2006. 114 p. Dissertação (Mestrado em Economia Aplicada) -Escola Superior de Agricultura "Luiz de Queiroz", São Paulo, 2006.

NOCE, R. et al. Concentração das exportações no mercado internacional de madeira serrada. Revista Árvore, Viçosa, v. 29, n. 3, p. 431-437, maio/jun. 2005.

NOCE, R. et al. Medida da desigualdade do mercado internacional de compensado. Cerne, v. 13, n. 1, p. 107-110, jan./mar. 2007.

NOCE, R. et al. Competitividade do Brasil no mercado internacional de aglomerado. Revista Árvore, Viçosa, v. 32, n. 2, p. 245-250, mar./abr. 2008.

POSSAS, M. L. et al. Ensaios sobre economia e direito da concorrência. São Paulo: Singular, 2002. $238 \mathrm{p}$.

POSSAS, M. L. Estruturas de mercado em oligopólio: economia e planejamento. 2. ed. São Paulo: Hucitec, 1999. 191 p.

RESENDE, M. Medidas de concentração industrial: uma resenha. Revista Análise Econômica, Porto Alegre, v. 12, n. 21, p. 24-33, jul./set. 1994.

RESENDE, M.; BOFF, H. Concentração industrial. In: KUPFER, D.; HASENCLEVER, L. (Org.). Economia industrial: fundamentos teóricos e práticas no Brasil. Rio de Janeiro: Campus, 2002. p. 73-90.

SCHERER, F. M.; ROSS, D. Industrial market structure and economic performance. 3rd ed. Boston: Houghton Mifflin, 1990. 270 p.

THEIL, H. Economics and information theory. Amsterdam: North-Holland, 1967. 488 p. 